CLINICAL STUDY

\title{
Association of plasma aldosterone with the metabolic syndrome in two German populations
}

\author{
Anke Hannemann $^{1, *}$, Christa Meisinger ${ }^{5, *}$, Martin Bidlingmaier $^{4}$, Angela Döring ${ }^{5}$, Barbara Thorand ${ }^{5}$, \\ Margit Heier ${ }^{5}$, Petra Belcredi ${ }^{5}$, Karl-Heinz Ladwig ${ }^{5}$, Henri Wallaschofski ${ }^{1}$, Nele Friedrich ${ }^{1}$, Sabine Schipf ${ }^{2}$, \\ Jan Lüdemann ${ }^{1}$, Rainer Rettig ${ }^{3}$, Jörg Peters ${ }^{3}$, Henry Völzke ${ }^{2}$, Jochen Seissler ${ }^{4}$, Felix Beuschlein ${ }^{4}$, Matthias Nauck ${ }^{1, *}$ \\ and Martin Reincke ${ }^{4, *}$ \\ ${ }^{1}$ Institute of Clinical Chemistry and Laboratory Medicine, ${ }^{2}$ Institute for Community Medicine and ${ }^{3}$ Institute of Physiology, Ernst-Moritz-Arndt-University \\ Greifswald, Ferdinand-Sauerbruch-Straße, D-17475 Greifswald, Germany, ${ }^{4}$ Medical Clinic Innenstadt, Ludwig-Maximilians-University Munich, 80336 \\ Munich, Germany and ${ }^{5}$ Institute of Epidemiology, Helmholtz Zentrum Munich, 85764 Neuherberg, Germany \\ (Correspondence should be addressed to A Hannemann; Email: anke.hannemann@uni-greifswald.de)
}

*(A Hannemann, C Meisinger, M Nauck and M Reincke contributed equally to this work)

\begin{abstract}
Objective: The aim of this study was to analyze the potential association of the plasma aldosterone concentration (PAC) with the metabolic syndrome (MetS) and its components in two German population-based studies.

Methods: We selected 2830 and 2901 participants (31-80 years) from the follow-ups of the Study of Health in Pomerania (SHIP)-1 and the Cooperative Health Research in the Region of Augsburg (KORA) F4 respectively. MetS was defined as the presence of at least three out of the following five criteria: waist circumference $\geq 94 \mathrm{~cm}(\mathrm{men}(\mathrm{m}))$ and $\geq 80 \mathrm{~cm}$ (women (w)); high-density lipoprotein (HDL) cholesterol $<1.0 \mathrm{mmol} / \mathrm{l}(\mathrm{m})$ and $<1.3 \mathrm{mmol} / \mathrm{l}(\mathrm{w})$; blood pressure $\geq 130 / 85 \mathrm{mmHg}$ or antihypertensive treatment; non-fasting glucose (SHIP-1) $\geq 8 \mathrm{mmol} / \mathrm{l}$, fasting glucose (KORA F4) $\geq 5.55 \mathrm{mmol} / \mathrm{l}$ or antidiabetic treatment; non-fasting triglycerides (SHIP-1) $\geq 2.3 \mathrm{mmol} / \mathrm{l}$, fasting triglycerides (KORA F4) $\geq 1.7 \mathrm{mmol} / \mathrm{l}$, or lipid-lowering treatment. We calculated logistic regression models by comparing the highest study- and sex-specific PAC quintiles versus all lower quintiles.

Results: MetS was common with $48.1 \%(\mathrm{~m})$ and $34.8 \%(\mathrm{w})$ in SHIP-1 and $42.7 \%(\mathrm{~m})$ and $27.5 \%(\mathrm{w})$ in KORA F4. Our logistic regression models revealed associations of PAC with MetS, elevated triglycerides, and decreased HDL cholesterol in SHIP-1 and KORA F4.

Conclusions: Our findings add to the increasing evidence supporting a relation between aldosterone and MetS and suggest that aldosterone may be involved in the pathophysiology of MetS and lipid metabolism disorders.
\end{abstract}

European Journal of Endocrinology 164 751-758

\section{Introduction}

The metabolic syndrome (MetS) is a cluster of multiple metabolic abnormalities, including visceral obesity, impaired glucose homeostasis, dyslipidemia, and hypertension. In the majority of cohort studies, associations of MetS with incident cardiovascular morbidity and mortality were observed $(1,2)$. Yet, there is an ongoing debate on whether MetS improves cardiovascular risk prediction above its single components $(3,4)$.

Aldosterone, a steroid hormone, produced in the zona glomerulosa of the adrenal cortex, is suggested to promote the development of MetS (5-7). Excessive levels of circulating aldosterone contribute to hypertension and cardiovascular disease (8). Patients with excessive chronic autonomous aldosterone, known as primary aldosteronism, exhibit a higher prevalence of MetS than patients with essential hypertension (9).
Current findings from cell culture experiments and animal models $(10,11)$ as well as from epidemiological studies (12) suggest a complex cross talk between the adipose tissue and the adrenal gland. Human adipocytes produce mineralocorticoid-releasing factors that stimulate aldosterone secretion, which in turn promotes adipogenesis $(11,13,14)$. Furthermore, epidemiological studies demonstrate that high plasma aldosterone concentrations (PAC) are associated with impaired insulin metabolic signaling, impaired pancreatic $\beta$-cell function, and insulin resistance $(15,16)$. In crosssectional analyses, associations of aldosterone with MetS were demonstrated $(9,17)$.

Although the previous cross-sectional studies were restricted to Black individuals $(17,18)$ or patients with primary aldosteronism (9), we aimed to explore the associations of PAC with MetS in the general population. We applied data from two large, population-based 
German studies: the Study of Health in Pomerania (SHIP), which was conducted in the northeast of Germany and the Cooperative Health Research in the Region Augsburg (KORA), which was conducted in the south of Germany. The two study regions differ with respect to the prevalence of arterial hypertension (19), with higher levels in northeast than in south Germany. Owing to the higher prevalence of hypertension, antihypertensive drugs, which often alter PAC levels, are used more frequently in northeast than in south Germany. In the present analyses, we also considered the influence of PAC-altering drugs (20) on our results.

\section{Materials and methods}

\section{Study populations}

The investigations in both the studies were carried out in accordance with the Declaration of Helsinki, including written informed consent of all participants. The survey and study methods of both the studies were approved by the institutional review boards (SHIP: ethics committee of the University of Greifswald; KORA: ethics committee of the Bavarian Chamber of Physicians, Munich).

\section{The study of health in Pomerania}

SHIP-1 is the first follow-up of the SHIP study, a population-based health survey conducted in the northeast of Germany in the cities of Greifswald, Stralsund, Anklam, and surroundings between 1997 and 2001. A total sample of 7008 subjects was drawn from the target population consisting of all German residents of the region aged 20-79 years. Study design and sampling methods were previously described (21). Of the 4308 participants of the SHIP-0 baseline examination, 3300 participated in the first 5-year follow-up, designated as SHIP-1. Between baseline and follow-up examinations, 234 individuals (5.4\%) had deceased and 126 individuals $(2.9 \%)$ had moved off the study region. Of the remaining 3948 eligible participants, 648 refused to participate in the follow-up, resulting in a response of $83.6 \%$.

\section{Cooperative health research in the region Augsburg}

The KORA F4 study is a follow-up of the KORA S4 study, a population-based health survey conducted in the city of Augsburg and two surrounding counties between 1999 and 2001. A total sample of 6640 subjects was drawn from the target population consisting of all German residents of the region aged 25-74 years. Study design and sampling methods were previously described (22). Of all the 4261 participants of the S4 baseline study, 3080 between 31 and 82 years of age also participated in the 7-year follow-up F4 study. Among the persons considered ineligible for F4, 176 (4\%) had died in the meantime, $206(5 \%)$ lived outside the study region or were completely lost to follow-up, and 12 $(0.2 \%)$ had demanded deletion of their address data. Of the remaining 3867 eligible persons, 174 could not be contacted, 218 were unable to come because they were too ill or had no time, and 395 were not willing to participate in this follow-up, giving a response of $79.6 \%$.

\section{Exclusions}

To create a comparable age range between SHIP-1 and KORA F4, we excluded all the participants younger than 31 years (SHIP-1, $n=187)$ and older than 80 years (SHIP-1, $n=131$; KORA F4, $n=31$ ). Further exclusion criteria were missing values for PAC (SHIP-1, $n=36$; KORA F4, $n=33$ ) or for one or more of the components of MetS (SHIP-1, $n=30$; KORA F4, $n=27$ ), pregnancy or missing data on pregnancy (SHIP-1, $n=16$; KORA F4, $n=12$ ), type 1 diabetes mellitus (SHIP-1, $n=7$; KORA F4, $n=6$ ), and renal disease defined as creatinine clearance $<50 \mathrm{ml} / \mathrm{min}$ (SHIP-1, $n=148$; KORA F4, $n=92$ ). Some participants were excluded for multiple reasons resulting in overall study populations of 2830 individuals in SHIP-1 and 2901 individuals in KORA F4. In both the studies, drug intake was categorized according to the anatomical therapeutical chemical (ATC) classification index. To evaluate the influence of PAC-altering medication (20) on our results, we repeated all the calculations in participants without intake of antiadrenergic agents (ATC C02), diuretics (ATC C03), $\beta$-blockers (ATC C07), calcium channel blockers (ATC CO8), or agents acting on the renin-angiotensin system (ATC C09) (SHIP-1, $n=1117$; KORA F4, $n=868$ ). This resulted in study sub-populations of 1713 individuals in SHIP-1 and 2033 individuals in KORA F4.

\section{Physical examinations}

During the physical examination, standardized measurements of height, weight, waist circumference, and blood pressure were performed. In both the studies, systolic and diastolic blood pressures were measured three times on the right arm of the seated participant, using an oscillometric digital blood pressure monitor (HEM-705CP, OMRON Corporation, Tokyo, Japan). For statistical analyses, the mean of the second and third measurements was used. Elevated blood pressure was defined as systolic or diastolic $\geq 130$ or $85 \mathrm{mmHg}$, respectively, or self-reported use of antihypertensive medication. Antihypertensive medication was defined following the guidelines of the German Hypertension Society (SHIP-1: 18th edition (23), KORA F4: 19th edition (24)). Fibrates (ATC C10AB) and nicotinic acids (ATC C10AD) were specified as lipid-lowering drugs. Insulin (ATC A10A) or oral antidiabetics (ATC A10B) were defined as antidiabetic drugs. Intake of estrogens 
was defined as oral contraceptives (ATC G03A) or hormone therapy (ATC G03C, G03D, G03F).

\section{Definition of MetS}

MetS was defined according to the joint interim statement of the International Diabetes Federation Task Force on Epidemiology and Prevention, National Heart, Lung, and Blood Institute, American Heart Association, World Heart Federation, International Atherosclerosis Society, and International Association for the Study of Obesity (25). MetS was assigned to participants fulfilling at least three out of the following five diagnostic criteria: central obesity, elevated fasting glucose, elevated triglycerides, decreased high-density lipoprotein (HDL) cholesterol, and elevated blood pressure (Table 1). In SHIP-1, blood was collected from mostly non-fasting participants, whereas in KORA F4, blood samples were taken from the participants who had been fasting for at least $10 \mathrm{~h}$. To compensate for the different blood sampling conditions in the two studies, modified cut-off points for elevated glucose and elevated triglycerides were applied. In KORA F4, elevated fasting glucose was defined as serum glucose concentration $\geq 5.55 \mathrm{mmol} / \mathrm{l}$ and elevated fasting triglycerides was defined as serum triglyceride concentration $\geq 1.7 \mathrm{mmol} / \mathrm{l}$. As previously established in SHIP-1 (26), elevated non-fasting glucose was defined as serum glucose concentration $\geq 8 \mathrm{mmol} / \mathrm{l}$ and elevated non-fasting triglycerides was defined as serum triglyceride concentration $\geq 2.3 \mathrm{mmol} / \mathrm{l}$. These cut-offs were adapted from Lidfeldt et al. (27), who used non-fasting blood samples from 6805 middle-aged Swedish women to identify the risk factors for cardiovascular disease and diabetes.

\section{Laboratory measurements}

In both the studies, PAC was measured in EDTA plasma, whereas glucose, triglycerides, HDL cholesterol, and potassium were measured in serum.
In SHIP-1, blood samples were taken from the cubital vein of participants in the supine position between 0800 and $2000 \mathrm{~h}$. PAC was measured by an RIA (CoatA-Count Aldosterone, Siemens Healthcare Diagnostics $\mathrm{GmbH}$, Eschborn, Germany). Inter- and intra-assay coefficients of variation (CV) were 15.7 and $5.4 \%$ in low as well as 3.8 and $2.3 \%$ in high concentrations respectively (28). Triglycerides and glucose were determined enzymatically (System: Hitachi 717; Reagents: Roche Diagnostics). HDL cholesterol was quantified by lipoprotein electrophoresis (System: HELENA SAS-3 system; Helena 7 BioSciences Europe, Tyne \& Wear, UK). Potassium was measured in serum by indirect potentiometry with ion-selective electrodes (QuikLYTE, Dade Behring, Eschborn, Germany).

In KORA F4, blood samples were taken from the cubital vein of seated participants in the morning. PAC was measured with an in-house immunofluorescence assay; inter- and intra-assay CV were 15.2 and $7.3 \%$ in low as well as 8.0 and $4.4 \%$ in high concentrations respectively (29). Triglycerides and glucose were determined enzymatically (System: Triglycerides: Dimension RxL, Glucose: Hitachi 717; Reagents: Dade Behring, Marburg, Germany). HDL cholesterol was directly quantified by an enzymatic method (System: Dimension RxL; Reagents: Dade Behring). Potassium was measured in serum by indirect potentiometry with ion-selective electrodes (QuikLYTE, Dade Behring).

\section{Statistical analyses}

To characterize the study populations, we report means \pm s.D. or medians (first and third quartile) for continuous variables and proportions for categorical variables. Group comparisons were performed using Kruskal-Wallis tests for continuous variables and $\chi^{2}$ tests for categorical variables. $P$ values $<0.05$ were considered statistically significant. In order to evaluate the relationship between PAC and MetS, logistic regression models were calculated with MetS and its

Table 1 Definition of MetS in the SHIP-1 and KORA F4 study participants.

\begin{tabular}{|c|c|c|}
\hline Components of MetS ${ }^{a}$ & SHIP-1 & KORA F4 \\
\hline Elevated waist circumference & Men $\geq 94 \mathrm{~cm}$ and women $\geq 80 \mathrm{~cm}$ & Men $\geq 94 \mathrm{~cm}$ and women $\geq 80 \mathrm{~cm}$ \\
\hline Elevated glucose & $\begin{array}{l}\text { Non-fasting glucose: } \geq 8 \mathrm{mmol} / \mathrm{l} \text { or antidiabetic } \\
\text { treatment (ATC A10A, A10B) }\end{array}$ & $\begin{array}{l}\text { Fasting glucose: } \geq 5.55 \mathrm{mmol} / \mathrm{l} \text { or antidiabetic } \\
\text { treatment }(\mathrm{ATC} A 10 \mathrm{~A}, \mathrm{~A} 10 \mathrm{~B})\end{array}$ \\
\hline Decreased HDL cholesterol & $\begin{array}{l}\text { Men }<1.0 \mathrm{mmol} / \mathrm{l} \text {, women }<1.3 \mathrm{mmol} / \mathrm{l} \text {, or lipid- } \\
\text { lowering treatment (ATC C10AB, A10AD) }\end{array}$ & $\begin{array}{l}\text { Men }<1.0 \mathrm{mmol} / \mathrm{l}, \text { women }<1.3 \mathrm{mmol} / \mathrm{l} \text {, or lipid- } \\
\text { lowering treatment }(\mathrm{ATC} C 10 \mathrm{AB}, \mathrm{A} 10 \mathrm{AD})\end{array}$ \\
\hline Elevated triglycerides & $\begin{array}{l}\text { Non-fasting triglycerides: } \geq 2.3 \mathrm{mmol} / \mathrm{l} \text { or lipid- } \\
\text { lowering treatment }(\mathrm{ATC} C 10 \mathrm{AB}, \mathrm{A} 10 \mathrm{AD})\end{array}$ & $\begin{array}{l}\text { Fasting triglycerides: } \geq 1.7 \mathrm{mmol} / \mathrm{l} \text { or lipid-lowering } \\
\text { treatment }(\mathrm{ATC} C \mathrm{C} 10 \mathrm{AB}, \mathrm{A} 10 \mathrm{AD})\end{array}$ \\
\hline Elevated blood pressure & $\begin{array}{l}\text { Systolic or diastolic blood pressures } \\
\geq 130 / 85 \mathrm{mmHg} \text { or self-reported antihyperten- } \\
\text { sive medication }{ }^{\mathrm{b}} \text { in a patient with a history of } \\
\text { hypertension }\end{array}$ & $\begin{array}{l}\text { Systolic or diastolic blood pressures } \\
\geq 130 / 85 \mathrm{mmHg} \text { or self-reported antihyperten- } \\
\text { sive medication }{ }^{\mathrm{b}} \text { in a patient with a history of } \\
\text { hypertension }\end{array}$ \\
\hline
\end{tabular}

ATC, anatomical therapeutical chemical classification index.

${ }^{a}$ MetS was assigned to participants meeting at least three of the five components mentioned in the table.

${ }^{\mathrm{b}}$ Antihypertensive medication was defined according to the Guidelines of the German Hypertension Society (SHIP 18th edition (23), KORA 19th edition (24)). 
Table 2 Study- and sex-specific 5th quintiles of PAC in SHIP-1 and KORA F4 study populations.

\begin{tabular}{llcc}
\hline & & \multicolumn{2}{c}{ 5th quintile of the PAC distribution $(\mathrm{ng} / \mathrm{l})$} \\
\cline { 3 - 4 } Study & Sex & $\begin{array}{c}\text { Including partici- } \\
\text { pants taking PAC- } \\
\text { altering medication }\end{array}$ & $\begin{array}{c}\text { Excluding partici- } \\
\text { pants taking PAC- } \\
\text { altering medication }\end{array}$ \\
\hline SHIP-1 & Males & $>75.0$ & $>75.0$ \\
& Females & $>63.0$ & $>61.0$ \\
KORA F4 & Males & $>58.0$ & $>56.2$ \\
& Females & $>70.0$ & $>72.0$ \\
\hline
\end{tabular}

components as dependent and PAC as independent variables. The SHIP-1 and KORA F4 study populations were divided according to the sex-specific quintiles of the respective PAC distribution (Table 2). Odds ratios and $95 \%$ confidence intervals (CI) for the highest versus all lower PAC quintiles are presented.

In a pooled analysis of SHIP-1 and KORA F4 data, we tested the interaction between study region and PAC. Suggestive interactions $(P<0.10)$ between study region and PAC were observed in models with MetS, elevated waist circumference, and elevated glucose as dependent variables. Therefore, we performed separate analyses for SHIP-1 and KORA F4.

To address confounding, we adjusted all models for age, sex, potassium, intake of estrogens (in females only), and intake of PAC-raising or PAC-lowering drugs (except for models with elevated blood pressure and MetS as outcome). All logistic regression models were weighted. Weights were accounted for dropouts between baseline and follow-up examinations and are based on sociodemographic and health-related variables. In addition to our main models, we performed a sensitivity analysis applying as alternative cut-off $6.5 \mathrm{mmol} / \mathrm{l}$ for elevated fasting glucose in KORA F4. We chose this cut-off according to the American Association of Clinical Endocrinologists, which recommends to define elevated fasting glucose as serum glucose concentration between 110 and $126 \mathrm{mg} / \mathrm{dl} \mathrm{(6-7} \mathrm{mmol/l)} \mathrm{(30).} \mathrm{Another} \mathrm{sensi-}$ tivity analysis was performed, applying an alternative cut-off for elevated blood pressure ( $\geq 140 / 90 \mathrm{mmHg}$ ), which was used in the 1998 WHO definition for MetS (30). All statistical analyses were performed with SAS 9.1 (SAS Institute, Inc., Cary, NC, USA).

\section{Results}

The SHIP-1 and KORA F4 study populations were similar in size with roughly the same proportions of male and female participants. SHIP-1 participants of both sexes had higher body mass index as well as higher systolic and diastolic blood pressure than KORA F4 participants (Table 3). MetS was common in both the study populations with $48.1 \%$ in male and $34.8 \%$ in female SHIP-1 participants, with $42.7 \%$ in male and $27.5 \%$ in female KORA F4 participants. Although elevated blood pressure was more frequent in SHIP-1 than in KORA F4, proportions of male and female participants with elevated waist circumference were similar. The proportion of participants who reported a diagnosis of diabetes was higher in SHIP-1 compared with KORA F4. Yet, the proportion of participants with elevated glucose level was higher in KORA F4 $(42.7 \%$ in men and $27.5 \%$ in women) than in SHIP-1 (11.6\% in men and $7.9 \%$ in women). In our sensitivity analysis with the modified glucose cut-off, proportions of KORA F4 participants with elevated glucose were $13.0 \%$ in men and $8.1 \%$ in women and thus substantially lower compared with the glucose cut-off applied in the main analysis. We further observed that more than twice as many SHIP-1 than KORA F4 participants had decreased HDL cholesterol, which may be partly due to the use of different methods for HDL cholesterol measurements.

The predominant single components in subjects with MetS were elevated waist circumference and elevated blood pressure. More than $90 \%$ of the SHIP-1 and KORA F4 participants with MetS had elevated waist circumference, independent of sex. In SHIP-1, 91\% of men and $90 \%$ of women with MetS had elevated blood pressure; the respective proportions in KORA F4 were $85 \%$ for men and $84 \%$ for women.

The proportion of Mets was higher in subjects with PAC levels in the 5th quintile than in subjects with PAC levels in the first to fourth quintiles. Totally, $49.1 \%$ of SHIP-1 subjects and $37.7 \%$ of KORA F4 subjects with PAC levels in the 5th quintile had MetS, but only $39.4 \%$ of SHIP-1 subjects and $34.4 \%$ of KORA F4 subjects with PAC levels in the first to fourth quintiles suffered from this metabolic condition.

In our logistic regression models including subjects taking PAC-altering medication, we observed statistically significant associations of high PAC with MetS and elevated triglycerides in both the studies (Table 4). We further detected associations of PAC with elevated waist circumference, elevated glucose, and decreased HDL cholesterol in SHIP-1 but not in KORA F4. In neither of the studies, associations of PAC with elevated blood pressure were observed. The analyses excluding participants taking PAC-altering medication revealed associations of high PAC with MetS, decreased HDL cholesterol, and elevated triglycerides.

Our sensitivity analysis using a modified cut-off for elevated glucose in KORA F4 partly changed our results. In the model including subjects taking PAC-altering medication, we now observed an association of high PAC with elevated glucose (odds ratio 1.65, 95\% CI: 1.28-2.12). In the model excluding subjects with PACaltering medication, no association was observed (odds ratio 1.47, 95\% CI: 0.96-2.26). This modified cut-off for elevated glucose provided results more similar to the results from SHIP-1. Our second sensitivity analysis using a modified cut-off for elevated blood pressure also 
Table 3 Characteristics of the SHIP-1 and KORA F4 study populations. Values are reported as mean (s.D.) for age, BMI, systolic and diastolic blood pressures, as median (first and third quartile) for PAC, and as proportions for categorical variables.

\begin{tabular}{|c|c|c|c|c|c|c|}
\hline \multirow[b]{2}{*}{ Characteristics } & \multicolumn{3}{|c|}{ Males } & \multicolumn{3}{|c|}{ Females } \\
\hline & SHIP-1 & $\mathrm{KORA} \mathrm{F}_{4}$ & $P$ & SHIP-1 & $\mathrm{KORA} \mathrm{F}_{4}$ & $P$ \\
\hline$n$ & 1369 & 1411 & & 1461 & 1490 & \\
\hline Age (years) & $55.2(13.3)$ & $55.9(12.9)$ & 0.17 & $53.6(12.8)$ & $55.0(12.6)$ & $<0.01$ \\
\hline $\mathrm{BMI}\left(\mathrm{kg} / \mathrm{m}^{2}\right)$ & $28.5(4.2)$ & $28.0(4.2)$ & $<0.01$ & $27.9(5.5)$ & $27.4(5.4)$ & $<0.01$ \\
\hline Systolic BP $(\mathrm{mmHg})$ & $137.4(18.5)$ & $127.4(17.0)$ & $<0.01$ & $128.1(19.1)$ & $116.8(17.6)$ & $<0.01$ \\
\hline Diastolic BP (mmHg) & $84.1(10.5)$ & $77.7(10.0)$ & $<0.01$ & $80.3(9.8)$ & $73.1(9.2)$ & $<0.01$ \\
\hline Diabetes (\%) & 12.1 & 7.4 & $<0.01$ & 9.0 & 5.6 & $<0.01$ \\
\hline MetS (\%) & 48.1 & 42.7 & NA & 34.8 & 27.5 & NA \\
\hline Elevated waist circumference (\%) & 67.3 & 66.7 & 0.74 & 67.6 & 69.4 & 0.30 \\
\hline Elevated glucose $(\%)$ & 11.6 & 42.4 & NA & 7.9 & 24.2 & NA \\
\hline Decreased HDL cholesterol (\%) & 54.6 & 15.6 & NA & 51.5 & 24.1 & NA \\
\hline Elevated triglycerides (\%) & 31.9 & 34.5 & NA & 16.1 & 17.2 & NA \\
\hline Elevated BP (\%) & 74.7 & 56.8 & $<0.01$ & 56.5 & 38.9 & $<0.01$ \\
\hline \multicolumn{7}{|l|}{ Intake of } \\
\hline Antihypertensive drugs (\%) & 37.0 & 31.4 & $<0.01$ & 33.7 & 26.6 & $<0.01$ \\
\hline PAC-raising drugs $(\%)^{\mathrm{a}}$ & 7.5 & 17.9 & $<0.01$ & 6.8 & 15.4 & $<0.01$ \\
\hline PAC-lowering drugs (\%) ${ }^{\mathrm{b}}$ & 41.1 & 31.9 & $<0.01$ & 37.0 & 27.7 & $<0.01$ \\
\hline $\begin{array}{l}\text { Oral contraceptives } \\
\text { ( } \% \text { of women }<50 \text { years) }\end{array}$ & - & - & & 17.0 & 17.2 & 0.92 \\
\hline $\begin{array}{l}\text { Systemic hormone therapy } \\
\text { ( } \% \text { of women } \geq 50 \text { years) }\end{array}$ & - & - & & 10.8 & 13.8 & 0.06 \\
\hline PAC (ng/l) & $45.0(29.0-68.0)$ & $35.2(24.0-52.0)$ & NA & $38.0(22.0-58.0)$ & $42.0(28.0-62.6)$ & NA \\
\hline
\end{tabular}

BP, blood pressure; PAC, plasma aldosterone concentration, NA, not applicable. Definitions of MetS and its components as referred to in Table 1. Definition of diabetes: self-reported physicians diagnosis. Differences between SHIP-1 and KORA F4 were assessed by Kruskal-Wallis test (continuous variables) and $\chi^{2}$ tests (categorical variables). $P$ values $<0.05$ were considered significant. Owing to different sampling conditions as well as different laboratory methods, group comparisons were not performed for MetS, elevated glucose, decreased HDL cholesterol, elevated triglycerides, and PAC.

aPAC-raising drugs: diuretics (ATC C03).

bPAC-lowering drugs: antiadrenergic agents (ATC C02), $\beta$-blockers (ATC C07), calcium channel blockers (ATC C08), and agents acting on the reninangiotensin system (ATC C09).

changed our results. With the new definition, $57.6 \%$ of men and $43.9 \%$ of women in SHIP- 1 as well as $42.6 \%$ of men and $31.5 \%$ of women in KORA F4 had elevated blood pressure. In SHIP-1, we now observed significant associations between high PAC and elevated blood pressure (model including subjects with PAC-altering medication: odds ratio $1.24,95 \% \mathrm{CI}$ : $1.04-1.48$; model excluding subjects with PAC-altering medication: odds ratio 1.31 , 95\% CI: 1.03-1.66). In KORA F4, no association was observed.

\section{Discussion}

We observed associations of PAC with MetS and lipid metabolism disorders in two studies of non-selected volunteers conducted in northeast and south Germany. Previous reports from cross-sectional studies demonstrated associations of aldosterone with MetS in Black population $(17,18)$ and a higher prevalence of MetS in primary aldosteronism than in essential hypertension (9). In a longitudinal analysis (7), using data from the

Table 4 Associations between high PAC with MetS and its components. Definitions of MetS and its components as referred to in Table 1. Odds ratios and $95 \%$ confidence intervals $(\mathrm{Cl})$ for fifth versus first to fourth PAC quintiles are displayed. Models were calculated separately for SHIP-1 and KORA F4. All logistic regression models were adjusted for age (continuous), sex (male/female), potassium (continuous), and intake of estrogens (in females only). Models including all subjects were further adjusted for intake of PAC-raising or PAC-lowering drugs (except for models with elevated blood pressure or MetS as outcome).

\begin{tabular}{|c|c|c|c|c|c|c|c|}
\hline \multirow[b]{2}{*}{ Model } & \multirow[b]{2}{*}{$n$} & \multirow[b]{2}{*}{ MetS } & \multicolumn{5}{|c|}{ Components of the MetS } \\
\hline & & & $\begin{array}{l}\text { Elevated waist } \\
\text { circumference }\end{array}$ & $\begin{array}{l}\text { Elevated } \\
\text { glucose }\end{array}$ & $\begin{array}{c}\text { Decreased HDL } \\
\text { cholesterol }\end{array}$ & $\begin{array}{l}\text { Elevated } \\
\text { triglycerides }\end{array}$ & $\begin{array}{l}\text { Elevated blood } \\
\text { pressure }\end{array}$ \\
\hline $\begin{array}{l}\text { SHIP-1 } \\
\text { OR (95\% Cl) } \\
\text { KORA F4 }\end{array}$ & 2830 & $1.64(1.38-1.95)$ & $1.71(1.41-2.09)$ & $1.49(1.14-1.95)$ & $1.34(1.13-1.58)$ & $1.47(1.22-1.77)$ & $1.11(0.93-1.34)$ \\
\hline OR $(95 \% \mathrm{Cl})$ & 2901 & $1.38(1.15-1.64)$ & $1.07(0.89-1.29)$ & $1.10(0.92-1.33)$ & $1.08(0.89-1.31)$ & $1.27(1.06-1.52)$ & $1.15(0.96-1.38)$ \\
\hline $\begin{array}{l}\text { SHIP-1 excludi } \\
\text { OR }(95 \% \mathrm{Cl})\end{array}$ & $\begin{array}{l}\text { participe } \\
1713\end{array}$ & $\begin{array}{c}\text { ants with PAC-alter } \\
1.51(1.19-1.91)\end{array}$ & $\begin{array}{l}\text { ring medication } \\
1.54(1.23-1.93)\end{array}$ & $1.24(0.67-2.30)$ & $1.36(1.10-1.69)$ & $1.42(1.09-1.84)$ & $1.09(0.87-1.37)$ \\
\hline $\begin{array}{l}\text { KORA F4 exclu } \\
\text { OR }(95 \% \mathrm{Cl})\end{array}$ & $\begin{array}{l}\text { partic } \\
2033\end{array}$ & $\begin{array}{c}\text { ipants with PAC-al } \\
1.28(1.01-1.62)\end{array}$ & $\begin{array}{r}\text { Itering medication } \\
0.99(0.81-1.21)\end{array}$ & $0.95(0.75-1.22)$ & $1.29(1.01-1.65)$ & $1.35(1.08-1.70)$ & $1.00(0.80-1.26)$ \\
\hline
\end{tabular}


Framingham Heart Study, aldosterone was associated with incident MetS. Our results add to the increasing evidence supporting a relation between aldosterone and MetS.

The biological mechanisms underlying the association of aldosterone with MetS are not yet fully understood. It has been suggested that elevated circulating aldosterone levels may cause increased inflammation and oxidative stress, which in turn may promote insulin resistance, impaired pancreatic $\beta$-cell function, endothelial dysfunction, and hypertension (31). Findings from observational studies support the evidence from experimental studies. In White, predominantly hypertensive individuals' relationship between PAC on the one hand and insulin, insulin resistance, and hyperinsulinemia on the other hand were observed (32). In Black subjects, an association of PAC with insulin and the homeostatic model assessment insulin resistance index was detected (18). Yet, in the same study (18), no association between PAC and glucose was observed. Our regression models revealed an association between PAC and elevated non-fasting glucose. We also observed an association between PAC and elevated fasting glucose when we applied the $6.5 \mathrm{mmol} / \mathrm{l}$ cut-off, but not when we applied the weaker $5.55 \mathrm{mmol} / \mathrm{l}$ cut-off. Both associations were lost in models excluding subjects taking PAC-altering medication. As in these models only $2.7 \%$ of SHIP-1 and $4.5 \%$ of KORA F4 participants had elevated glucose, this might be a power problem. Whether there are associations of PAC with insulin in SHIP-1 or KORA F4 was not addressed, since we currently do not have any data on insulin concentrations from either study.

Consistent with our findings, associations of PAC with the obesity-related components of MetS including decreased HDL cholesterol (17), elevated triglycerides (18), and elevated waist circumference $(17,18)$ were observed in Black subjects. It has been suggested that in a self-strengthening process, human adipocytes may stimulate aldosterone production by producing mineralocorticoid-releasing factors, which in turn can promote adipogenesis and inflammation $(13,14)$. Our analyses revealed associations of high PAC with MetS, elevated triglycerides, and decreased HDL cholesterol in SHIP-1 and KORA F4 as well as elevated waist circumference only in SHIP-1. The corresponding odds ratios of all associations were higher in SHIP-1 than in KORA F4. Previous studies $(19,33)$ demonstrated that the prevalence of cardiovascular risk factors such as smoking or obesity vary between the SHIP-1 and the KORA F4 populations. We assume that the higher burden of cardiovascular and metabolic risk factors in northeast compared with south Germany partially accounts for the higher strength of the associations of PAC with the components of MetS in SHIP-1 versus KORA F4.

We further assume that our results have been affected by the intake of PAC-altering medication, as in all models, except HDL cholesterol, the strength of the associations decreased when subjects taking PACaltering medication were excluded versus included. At the same time, the associations observed in the models excluding versus including subjects taking PAC-altering medication were essentially the same. This implies that independent of whether PAC levels are altered by drug intake, high PAC levels are associated with MetS and its components.

A further conceivable explanation for the differences between SHIP-1 and KORA F4 may be unaddressed confoundingly. Salt intake, for instance, affects both PAC and blood pressure (34). Unfortunately, salt intake was not measured in our cohorts. Furthermore, genetic variations between the two populations (35) may have influenced our results.

The contribution of excessive aldosterone levels to hypertension is unquestioned $(8,36)$. Results from two longitudinal analyses using data from North America and France $(37,38)$ demonstrated that serum aldosterone levels may contribute to the development of hypertension. Other cross-sectional studies suggest that the association of aldosterone with elevated blood pressure is generally stronger in Black than in White individuals (39) or is only present in older individuals (mean age 61 years) (17). In contrast to these studies $(17,39)$, our cross-sectional analyses did not reveal a significant association between PAC and elevated blood pressure, which may have different reasons. First, in the model excluding subjects taking PAC-altering medication, the excluded participants represent the majority of participants with elevated blood pressure (55.5\%) and MetS (58.1\%). This introduces a selection in the study population and reduces statistical power. Secondly, we observed no association between high PAC and elevated blood pressure defined as systolic or diastolic $\geq 130 / 85 \mathrm{mmHg}$. When elevated blood pressure was defined as systolic or diastolic $\geq 140 / 90 \mathrm{mmHg}$, we observed an association in SHIP-1. This might imply that the association of high PAC and elevated blood pressure increases with severity of disease.

The reported prevalence of MetS in the SHIP-1 and KORA F4 study populations were impressively high. In a previous publication (40) using KORA data, it was shown that the prevalence of MetS strongly depends on the criteria used to define the condition. In a population of elderly KORA participants, the prevalence of MetS varied between $24-46 \%$ in women and $28-57 \%$ in men, depending on the definition used (40). We, therefore, applied a recent definition for MetS, published by several major organizations, which represents an attempt to harmonize MetS (25).

Major strengths of our study are the population-based study design, the large number of participants in both studies and the standardized data collection performed by trained and certified examiners.

Limitations arise from technical differences in the measurements of PAC, plasma glucose, triglycerides, 
and HDL cholesterol between SHIP-1 and KORA F4. Prior to the present analyses, we examined the influence of blood sampling time and fasting status on PAC and found no significant effect (39). By creating study-specific quintiles for PAC and using modified cut-offs for non-fasting levels in the definition of MetS, we corrected for these differences. Nevertheless, we cannot rule out that the different methods used to measure PAC, plasma glucose, HDL cholesterol, or triglycerides in the two studies introduced some bias. Another limitation of our study is that all participants were under random sodium diet and under regular medication, including PAC-altering drugs. In contrast to clinical studies with small samples, SHIP-1 and KORA F4 are large, observational studies, in which it is not possible to change antihypertensive treatment or dietary habits of our participants. Moreover, we used single-occasion measurements from our participants. It is arguable whether single measurements can appropriately represent the PAC, plasma glucose, HDL cholesterol, or triglyceride profiles of our subjects. Unfortunately, for logistic reasons, it is impossible to repeat blood sampling in our population-based studies.

Taken together, our results obtained in non-selected, White individuals from northeast or south Germany revealed associations of PAC with MetS and lipid metabolism disorders. Owing to the high prevalence of MetS and its components in the general population, future research should focus on a better understanding of the mechanism underlying the associations of PAC with MetS and lipid metabolism disorders.

\section{Declaration of interest}

The authors declare that there is no conflict of interest that could be perceived as prejudicing the impartiality of the research reported.

\section{Funding}

The SHIP research platform is part of the Community Medicine Research net (CMR) of the University of Greifswald, Germany, which is funded by the Federal Ministry of Education and Research, the Ministry of Cultural Affairs, as well as the Social Ministry of the Federal State of Mecklenburg-West Pomerania. The CMR encompasses several research projects that share data of the population-based Study of Health in Pomerania (SHIP; http://ship.community-medicine.de). Instand e.V. provided partial grant support for the determination of plasma samples and data analysis.

The KORA research platform and the KORA Augsburg studies are financed by the Helmholtz Zentrum München, German Research Center for Environmental Health $(\mathrm{GmbH})$, which is funded by the German Federal Ministry of Education, Science, Research, and Technology and by the State of Bavaria. M Reincke is supported by grants from the Else Kröner Fresenius Stiftung and the German Research Organization (Re 752/17-1).

\section{Acknowledgements}

The contribution to data collection made by field workers, technicians, interviewers, and computer assistants in both studies is gratefully acknowledged.

\section{References}

1 Isomaa B, Almgren P, Tuomi T, Forsen B, Lahti K, Nissen M, Taskinen MR \& Groop L. Cardiovascular morbidity and mortality associated with the metabolic syndrome. Diabetes Care 200124 683-689. (doi:10.2337/diacare.24.4.683)

2 Gami AS, Witt BJ, Howard DE, Erwin PJ, Gami LA, Somers VK \& Montori VM. Metabolic syndrome and risk of incident cardiovascular events and death: a systematic review and meta-analysis of longitudinal studies. Journal of the American College of Cardiology 200749 403-414. (doi:10.1016/j.jacc.2006.09.032)

3 Kahn R. Metabolic syndrome: is it a syndrome? Does it matter? Circulation 2007115 1806-1810 (discussion 1811). (doi:10. 1161/CIRCULATIONAHA.106.658336)

4 Beaser RS \& Levy P. Metabolic syndrome: a work in progress, but a useful construct. Circulation $2007 \mathbf{1 1 5} 1812-1818$ (discussion 1818). (doi:10.1161/CIRCULATIONAHA.106.673616)

5 Sowers JR, Whaley-Connell A \& Epstein M. Narrative review: the emerging clinical implications of the role of aldosterone in the metabolic syndrome and resistant hypertension. Annals of Internal Medicine 2009150 776-783.

6 Zennaro MC, Caprio M \& Feve B. Mineralocorticoid receptors in the metabolic syndrome. Trends in Endocrinology and Metabolism 2009 20 444-451. (doi:10.1016/j.tem.2009.05.006)

7 Ingelsson E, Pencina MJ, Tofler GH, Benjamin EJ, Lanier KJ, Jacques PF, Fox CS, Meigs JB, Levy D, Larson MG, Selhub J, D'Agostino RB Sr, Wang TJ \& Vasan RS. Multimarker approach to evaluate the incidence of the metabolic syndrome and longitudinal changes in metabolic risk factors: the Framingham Offspring Study. Circulation 2007116 984-992. (doi:10.1161/CIRCULATIONAHA.107.708537)

8 Stewart PM. Mineralocorticoid hypertension. Lancet 1999353 1341-1347. (doi:10.1016/S0140-6736(98)06102-9)

9 Fallo F, Veglio F, Bertello C, Sonino N, Della Mea P, Ermani M, Rabbia F, Federspil G \& Mulatero P. Prevalence and characteristics of the metabolic syndrome in primary aldosteronism. Journal of Clinical Endocrinology and Metabolism 200691 454-459. (doi:10. 1210/jc.2005-1733)

10 Ronconi V, Turchi F, Bujalska IJ, Giacchetti G \& Boscaro M. Adipose cell-adrenal interactions: current knowledge and future perspectives. Trends in Endocrinology and Metabolism 200819 100-103. (doi:10.1016/j.tem.2008.01.004)

11 Ehrhart-Bornstein M, Lamounier-Zepter V, Schraven A, Langenbach J, Willenberg HS, Barthel A, Hauner H, McCann SM, Scherbaum WA \& Bornstein SR. Human adipocytes secrete mineralocorticoid-releasing factors. PNAS $2003 \mathbf{1 0 0}$ 14211-14216. (doi:10.1073/pnas. 2336140100)

12 Goodfriend TL, Egan BM \& Kelley DE. Aldosterone in obesity. Endocrine Research $1998 \mathbf{2 4}$ 789-796. (doi:10.3109/0743580 9809032689)

13 Guo C, Ricchiutti V, Lian B, Yao T, Coutinho P, Romero J, Li J, Williams G \& Adler G. Mineralocorticoid receptor blockade reverses obesity-related changes in expression of adiponectin, peroxisome proliferator-activated receptor-gamma, and proinflammatory adipokines. Circulation $2008 \quad 117 \quad 2253-2261$. (doi:10.1161/CIRCULATIONAHA.107.748640)

14 Caprio M, Feve B, Claes A, Viengchareun S, Lombes M \& Zennaro MC. Pivotal role of the mineralocorticoid receptor in corticosteroid-induced adipogenesis. FASEB Journal $2007 \mathbf{2 1}$ 2185-2194. (doi:10.1096/fj.06-7970com)

15 Roberge C, Carpentier AC, Langlois MF, Baillargeon JP, Ardilouze JL, Maheux P \& Gallo-Payet N. Adrenocortical dysregulation as a major player in insulin resistance and onset of obesity. American Journal of Physiology. Endocrinology and Metabolism 2007293 E1465-E1478. (doi:10.1152/ajpendo.00516.2007)

16 Lastra-Lastra G, Sowers JR, Restrepo-Erazo K, Manrique-Acevedo C \& Lastra-Gonzalez G. Role of aldosterone and angiotensin II in insulin resistance: an update. Clinical Endocrinology 200971 1-6. (doi:10.1111/j.1365-2265.2008.03498.x) 
17 Bochud M, Nussberger J, Bovet P, Maillard MR, Elston RC, Paccaud F, Shamlaye C \& Burnier M. Plasma aldosterone is independently associated with the metabolic syndrome. Hypertension $2006 \mathbf{4 8}$ 239-245. (doi:10.1161/01.HYP.0000231338. 41548.fc)

18 Kidambi S, Kotchen JM, Grim CE, Raff H, Mao J, Singh RJ \& Kotchen TA. Association of adrenal steroids with hypertension and the metabolic syndrome in Blacks. Hypertension $2007 \mathbf{4 9}$ 704-711. (doi:10.1161/01.HYP.0000253258.36141.c7)

19 Meisinger C, Heier M, Volzke H, Lowel H, Mitusch R, Hense HW \& Ludemann J. Regional disparities of hypertension prevalence and management within Germany. Journal of Hypertension $2006 \mathbf{2 4}$ 293-299. (doi:10.1097/01.hjh.0000200508.10324.8e)

20 Funder JW, Carey RM, Fardella C, Gomez-Sanchez CE, Mantero F, Stowasser M, Young WF Jr \& Montori VM. Case detection, diagnosis, and treatment of patients with primary aldosteronism: an endocrine society clinical practice guideline. Journal of Clinical Endocrinology and Metabolism 200893 3266-3281. (doi:10. 1210/jc.2008-0104)

21 Volzke H, Alte D, Schmidt CO, Radke D, Lorbeer R, Friedrich N, Aumann N, Lau K, Piontek M, Born G, Havemann C, Ittermann T, Schipf S, Haring R, Baumeister SE, Wallaschofski H, Nauck M, Frick S, Arnold A, Junger M, Mayerle J, Kraft M, Lerch MM, Dorr M, Reffelmann T, Empen K, Felix SB, Obst A, Koch B, Glaser S, Ewert R, Fietze I, Penzel T, Doren M, Rathmann W, Haerting J, Hannemann M, Ropcke J, Schminke U, Jurgens C, Tost F, Rettig R, Kors JA, Ungerer S, Hegenscheid K, Kuhn JP, Kuhn J, Hosten N, Puls R, Henke J, Gloger O, Teumer A, Homuth G, Volker U, Schwahn C, Holtfreter B, Polzer I, Kohlmann T, Grabe HJ, Rosskopf D, Kroemer HK, Kocher T, Biffar R, John U \& Hoffmann W. Cohort profile: the study of health in Pomerania. International Journal of Epidemiology, 2010 In press. (doi:10.1093/ije/ dyp394)

22 Holle R, Happich M, Lowel H \& Wichmann HE. KORA - a research platform for population based health research. Gesundheitswesen 200567 (Supplement 1) S19-S25. (doi:10.1055/s-2005-858235)

23 Empfehlungen zur Hochdruckbehandlung. Recommendation for the Treatment of Hypertension, 18th edn. Heidelberg: Deutsche Liga zur Bekämpfung des hohen Blutdruckes e.V., 2003/2004.

24 Empfehlungen zur Hochdruckbehandlung. Recommendation for the Treatment of Hypertension, 19th edn. Heidelberg: Deutsche Liag zur Bekämpfung des hohen Blutdruckes e.V., 2007.

25 Alberti KG, Eckel RH, Grundy SM, Zimmet PZ, Cleeman JI, Donato KA, Fruchart JC, James WP, Loria CM \& Smith SC Jr. Harmonizing the metabolic syndrome: a joint interim statement of the International Diabetes Federation Task Force on Epidemiology and Prevention; National Heart, Lung, and Blood Institute; American Heart Association; World Heart Federation; International Atherosclerosis Society; and International Association for the Study of Obesity. Circulation $2009 \mathbf{1 2 0} 1640-1645$. (doi:10.1161/CIRCULATIONAHA.109.192644)

26 Schipf S, Alte D, Völzke H, Friedrich N, Haring R, Lohmann T, Rathmann W, Nauck M, Felix SB, Hoffmann W, John U \& Wallaschofski H. Prävalenz des Metabolischen Syndroms in Deutschland: Ergebnisse der Study of Health in Pomerania (SHIP). Diabetologie und Stoffwechsel 20105 161-168. (doi:10. 1055/s-0030-1247406)

27 Lidfeldt J, Nyberg P, Nerbrand C, Samsioe G, Schersten B \& Agardh CD. Socio-demographic and psychosocial factors are associated with features of the metabolic syndrome. The Women's Health in the Lund Area (WHILA) study. Diabetes, Obesity and Metabolism 20035 106-112. (doi:10.1046/j.1463-1326.2003. 00250.x)

28 Hannemann A, Friedrich N, Ludemann J, Volzke H, Rettig R, Peters J, Reincke M, Doring A, Nauck M \& Wallaschofski H. Reference intervals for aldosterone, renin, and the aldosterone-to-renin ratio in the population-based study of health in Pomerania (SHIP-1). Hormone and Metabolic Research 201042 392-399. (doi:10.1055/ s-0030-1247545)

29 Manolopoulou J, Bielohuby M, Caton SJ, Gomez-Sanchez CE, Renner-Mueller I, Wolf E, Lichtenauer UD, Beuschlein F, Hoeflich A \& Bidlingmaier M. A highly sensitive immunofluorometric assay for the measurement of aldosterone in small sample volumes: validation in mouse serum. Journal of Endocrinology 2008196 215-224. (doi:10.1677/JOE-07-0134)

30 Grundy SM, Cleeman JI, Daniels SR, Donato KA, Eckel RH, Franklin BA, Gordon DJ, Krauss RM, Savage PJ, Smith SC Jr, Spertus JA \& Costa F. Diagnosis and management of the metabolic syndrome: an American Heart Association/National Heart, Lung, and Blood Institute Scientific Statement. Circulation 2005112 2735-2752. (doi:10.1161/CIRCULATIONAHA.105.169404)

31 Whaley-Connell A, Johnson MS \& Sowers JR. Aldosterone: role in the cardiometabolic syndrome and resistant hypertension. Progress in Cardiovascular Diseases 201052 401-409. (doi:10. 1016/j.pcad.2009.12.004)

32 Colussi G, Catena C, Lapenna R, Nadalini E, Chiuch A \& Sechi LA. Insulin resistance and hyperinsulinemia are related to plasma aldosterone levels in hypertensive patients. Diabetes Care 200730 2349-2354. (doi:10.2337/dc07-0525)

33 Moebus S, Hanisch J, Bramlage P, Losch C, Hauner H, Wasem J \& Jockel KH. Regional differences in the prevalence of the metabolic syndrome in primary care practices in Germany. Deutsches Ärzteblatt International $2008 \quad 105 \quad 207-213$. (doi:10.3238/ artzebl.2008.0207)

34 Fujita T. Aldosterone in salt-sensitive hypertension and metabolic syndrome. Journal of Molecular Medicine $2008 \mathbf{8 6} 729-734$. (doi:10.1007/s00109-008-0343-1)

35 Steffens M, Lamina C, Illig T, Bettecken T, Vogler R, Entz P, Suk E-K, Toliat MR, Klopp N, Caliebe A, König IR, Köhler K, Lüdemann J, Lacava AD, Fimmers R, Lichtner P, Ziegler A, Wolf A, Krawczak M, Nürnberg P, Hampe J, Schreiber S, Meitinger T, Wichmann HE, Roeder K, Wienker TF \& Baur MP. SNP-based analysis of genetic substructure in the German population. Human Heredity $2006 \mathbf{6 2}$ 20-29. (doi:10.1159/000095850)

36 Connell JM, MacKenzie SM, Freel EM, Fraser R \& Davies E. A lifetime of aldosterone excess: long-term consequences of altered regulation of aldosterone production for cardiovascular function. Endocrine Reviews 200829 133-154. (doi:10.1210/er.20070030)

37 Meneton P, Galan P, Bertrais S, Heudes D, Hercberg S \& Menard J. High plasma aldosterone and low renin predict blood pressure increase and hypertension in middle-aged Caucasian populations. Journal of Human Hypertension 200822 550-558. (doi:10.1038/ jhh.2008.27)

38 Vasan RS, Evans JC, Larson MG, Wilson PW, Meigs JB, Rifai N, Benjamin EJ \& Levy D. Serum aldosterone and the incidence of hypertension in nonhypertensive persons. New England Journal of Medicine 2004351 33-41. (doi:10.1056/NEJMoa033263)

39 Grim CE, Cowley AW Jr, Hamet P, Gaudet D, Kaldunski ML, Kotchen JM, Krishnaswami S, Pausova Z, Roman R, Tremblay J \& Kotchen TA. Hyperaldosteronism and hypertension: ethnic differences. Hypertension 200545 766-772. (doi:10.1161/01. HYP.0000154364.00763.d5)

40 Rathmann W, Haastert B, Icks A, Giani G, Holle R, Koenig W, Lowel $\mathrm{H} \&$ Meisinger $\mathrm{C}$. Prevalence of the metabolic syndrome in the elderly population according to IDF, WHO, and NCEP definitions and associations with C-reactive protein: the KORA Survey 2000. Diabetes Care 200629 461. (doi:10.2337/diacare. 29.02.06.dc05-1885)

Received 19 January 2011

Accepted 28 February 2011 